\title{
Portfolio Theory and Electricity Forward Markets
}

\author{
Michal MICHALOVSKÝ $\hat{Y}^{*}-$ Igor PAHOLOK ${ }^{* *}$
}

\section{Introduction}

The deregulation of electricity markets throughout the developed world has triggered a new perception of the electricity sector among the entities concerned. The sector is no longer a state-running monopoly, but, through structural legislation reforms, has changed into a competitive business with newly emerged risks and profits subjected to free market conditions. Thus, producers, agents and suppliers have to deal with volatile prices of energy commodities and electricity itself. In order to stabilize their profits, they turn attention to forward electricity markets with various negotiable instruments to hedge their positions accordingly. In this essay, we aim to look closer at these forward markets and examine whether one can take the futures' quotations as estimates for the spot prices, or rather, these reflect the market equilibrium of supply and demand for hedging instruments. In particular, we focus on the so called forward risk premium, presented in forward contracts, that gives us an idea of what the relationship between the futures' quotations and underlying asset is about. We provide theoretical background of the risk premium, and using empirical data from selected European power exchanges investigate what shapes its values.

\# This paper was supported by grant project "Behavior of Investment Instruments in the Context of Financial Crisis" registered by the Internal Grant Competition under the registration number IG102030/8/2010 and by grant project "Market Risk and Financial Derivatives" registered by the Czech Science Foundation under the registration number 402/09/0732.

Bc. Michal Michalovský - graduate student; Faculty of Finance and Accounting, University of Economics Prague, W. Churchill sq. 4, 13067 Prague 3, Czech Republic; <michalovsky@institutee.cz>.

** Ing. Igor Paholok - Ph.D. student; Department of Banking and Insurance, Faculty of Finance and Accounting, University of Economics Prague, W. Churchill sq. 4, 13067 Prague 3, Czech Republic; <paholok@institutee.cz>. 
The first subsection of Section 2 in this paper provides the theoretical background for the forward risk premium. The second subsection contains a review of the equilibrium model proposed by Bessembinder Lemon (2002), also known as the B-L model. The third subsection goes on by applying the portfolio theory on electricity market and its participants. Section 3 describes used data set, results of computing of expost risk premia, and testing for components of the risk premia using B-L model and applied portfolio theory. The Section 4 analyzes the tests' results and concludes.

\section{Theoretical review}

\subsection{Theoretical background of the risk premium}

Since electricity cannot be economically stored, we have lost the basic argument that the price of a forward contract is always determined by a non-arbitrager approach. Under this approach, any storable commodity would never be bought by an outside speculator, and be stored for a given period of time only to be sold back on the forward market with a locked profit. Taking into account the storage cost and interest rate (and yield if possible), the arbitrager normally cannot sell his underlying asset in the forward market for a higher price than the sum of his total costs. The quotations of a forward contract should thus reflect these costs and provide the speculator with no advantage.

However, in order to understand the relationship between spot and forward prices, as in the case of electricity and other non-storable commodities, we have to adopt recent idea of forward risk premium. Market risk premium deals with expected spot prices, which are estimations of the future behavior of current spot prices. Developing an appropriate statistical model for such a task involves mainly finding a dependence of electricity prices on relating prices of energy commodities, technical time series of producers' capacities, hydropower reservoir levels, seasonality and so forth according to price patterns and performance of a particular market. The simple formula of the ex-ante risk premia can be then written as:

$$
\pi_{t, T}=F_{t, T}^{w}-E\left(S_{T}\right)
$$


Where $\pi_{t, T}$ depicts risk premium in present-day time $t$ to be realized in time $T . F_{t, T}^{w}$ depicts today's forward price for the contract with a delivery period in time T.E $\left(S_{T}\right)$ means expected spot price in time $T$. Comprehensive estimation models have been developed by Bessembinder - Lemmon (2002); Lucia and Torro (2008) and Cartea and Villaplana (2008).

On the contrary, ex-post risk premium is defined as a difference between the price of the forward contract and the realized spot price over the delivery period. The most obvious amenity of this approach is availability of all necessary data for our calculations. We thus accurately compute realized risk premium of a given forward contract. The formula is written as:

$$
\pi_{t, T}=F_{t, T}^{w}-S_{T}
$$

Risk premium in the delivery period in time $T$ is given by subtracting the average prices of any periods in forward contract lifetime $F_{t, T}^{w}$ (for example one month to delivery) from the average spot price of delivery $S_{T}$. Under the assumption that evolution of risk premium is anticipated by entities on the base of rational expectations, we think both ex-ante and ex-post premiums equal with just a residual noise, $\varepsilon_{t, T}$ :

$$
F_{t, T}^{w}-S_{T}=\pi_{t, T}+\varepsilon_{t, T}
$$

However, due to the limited number of participants on electricity markets and often sharp changes of electricity prices, this leads us to the idea that the assumption is rather imperfect and that the premium is driven by outside forces instead of expectations. In spite of that, we opt in this essay to stand for it and calculate ex-post premium on available data with a discussion over its potential implication and by that to contribute to amount of similar studies conducted on different electricity markets, i.e. Botterud et al. (2002), Longstaff and Wang (2004), Furio and Meneu (2009), Pietz (2009) etc.

The basic idea of forward risk premium emphasizes that forward prices do not stand for reliable estimates of futures spot prices. While analyzing electricity prices, we should consider them rather as a current 
equilibrium of interaction between supply and demand, as though they are, hedging instruments. This is due to the fact that since the deregulation, the electricity markets have not been widely attended by outside speculators due to tough capital and IT admission requirements or lack of necessary information. Entities already operate on the markets that are mostly interested in physical delivery, as done in hedging. Both the producers and the consumers of electricity have contradictory reasons for hedging through forward instruments. The first hedge to stabilize their level of profit, and the latter to fix the price and, by extension, their costs. The strength of both sides thus defines the forward risk premium.

Whether the value of the premium is negative or positive it is closely tied with the definition of the forward contract and its convergence into the spot price of the underlying asset. Being the state of the forward price approaching the spot price from below called normal backwardation, we speak about negative risk premium. In contrast, in the case of contango, when the forward price converges to the spot from above, we call it positive risk premium.

Consequently, negative premium occurs as a result of prevailing hedging pressure on producers' side. They perceive higher risks of instability of either costs or revenues by increasing in prices of an input for production or decreasing in the spot prices while selling their electricity. Because of this, they seek to hedge the newly emerged risks by fixing the electricity price on the forward market, and therefore enter into the short positions of the contracts with future delivery. As a result, the market price of such a contract decreases below the expected spot price and the risk premium is driven to be negative.

Analogically, positive risk premium reflects greater hedging effort on the retailers' side. Incentives for that are motivated only by securing their costs since the actual consumers of the electricity are committed to longterm contracts without the excessive price shifts when renewing. Therefore, when trying to secure the price of future purchases, they enter into the long futures positions, which drives the forward prices above expected spot prices, causing the risk premium is to be positive.

More importantly, one of the main features of the electricity markets is that as the upward price spikes on the spot market the spikes tend to occur rather frequently because of unexpected immediate changes in 
Michalovský, M. - Paholok, I.: Portfolio Theory and Electricity Forward Markets.

demand and the greater hedging incentives still persist on retailers. We therefore assume that the overall market risk premium should be positive.

\subsection{B-L Equilibrium model}

An influential model dealing with the relationship between futures and spot prices is carefully proposed by Bessembinder and Lemmon (2002). Their equilibrium model suggests the risk premium as being dependent on variance and skewness of the spot price. The following regression can then be directly tested:

$$
\pi_{t, T}=a+b \cdot \operatorname{VAR}\left[S_{T}\right]+c \cdot \operatorname{SKEW}\left[S_{T}\right]+\varepsilon_{t, T},
$$

Where $\operatorname{VAR}\left[S_{T}\right]$ and $S K E W\left[S_{T}\right]$ denote variance and skewness of the spot price over the delivery period, respectively $a, b, c$ stand for the estimated parameters. According to the model, the risk premium is negatively related to the variance of the spot price due to short market hedging pressure. This happens when the expected variance of the spot price is high and retailers seek to stabilize the level and variability of the profits by offsetting their long positions in order to achieve lower cashflow fluctuations when contracts are physically settled. In other words, they perceive the higher expected variance of the spot price as a threat and try to avoid that by reducing the amount of forward contracts held, which are otherwise required to be settled during the delivery.

Skewness, on the other hand, is related to the risk premium positively, that is, the higher asymmetry of the probability distribution of the spot price, the higher premium we can expect. Value of skewness reflects the frequent upward spikes in the electricity spot market. Distribution of the spot prices contain a few extremely high values (spikes) and therefore the bulk of the values are to be found to the left of the mean. This explains that skewness in the case of electricity is expected to be overall positive. By their experience, the participants have apprehended that feature of the markets, and encourage themselves to hedge against the unexpected spikes by demanding the forward contracts. In addition, the sellers of these contracts require the premium for bearing the greater spot price risk. The risk premium is thus to be driven upward.

Several empirical papers have been concerned with validation of the B-L model described above. Lucia and Torro (2008) provide us with 
evidence from NordPool, Scandinavian electricity exchange, using weekly futures' data for sample period from 1998 to 2007. They found a strong indication that the model was not valid for the whole sample period due to non-significant parameters and very low R-square coefficients. However, excluding the supply-shock period from late 2002 to early 2003, they present interesting results. On the pre-shock period, the parameters are consistent with the B-L model, that is, negative (positive) risk premium dependence on variance (skewness), with an Rsquare as high as $30 \%$ in one week ahead futures contracts. The postshock period shows results that contrast to the B-L model. Estimated parameters for variance are positive and non-significant, except for one week ahead with a $10 \%$ significance level, while parameters for skewness are negative and significant. R-square average, is much lower than that of the pre-shock period. They therefore concluded that the market perception had undergone a considerable change during the supply-shock period that caused the B-L model to be no longer valid.

The Spanish electricity market is analyzed by Furio and Meneu (2009). They ran the regression on monthly futures data for a sample period from 2003 to 2008. They modified the equation a little by adding the observation of realized risk premium in the previous month $\pi(t-1$, $T-1)$. As a result, they obtain unusually high R-square coefficient of determination of $46 \%$. However, their findings during the whole sample period stand for only partial confirmation of the B-L model. Although the risk premium negatively depends on variance with high level of significance, the parameter of skewness is non-significant.

While looking at the short-term day-ahead hourly futures on the American PJM electricity market, Longstaff and Wang (2004), with a dataset consisting of years 2000 to 2002, they were able to fully confirm the implications of the B-L model by discovering significant negative (positive) dependence of the risk premium on variance (skewness) in the hourly prices. The R-square found is about $20 \%$.

\subsection{Portfolio theory in electricity forward markets}

Although the previously described B-L equilibrium model is primarily based on the portfolio theory, the model construction deals with several specific assumptions about production function that might reduce the model's universality. Therefore, we present an electricity forward risk premium model, based on and strictly connected to the Markowitz 
portfolio theory and its application for Tobin's model of money demand as presented in Kodera (2001).

Similarly as for the model specified above we assume that electricity forward contracts are generally traded on the wholesale electricity market. We divide the market participants into two groups, producers and retailers. We assume that all of the below specified characteristics (as market expectations of the producers and retailers, the utility function, electricity production costs function of producers etc.) are the same, or at least very similar for all group members. All other assumptions, valid for the original portfolio theory, are applied in our analysis as well.

Behavior of speculators, the third possible subject group, is identical to producers' for all of the speculators, whose position at time $t$, on forward delivery period $T$, is long. Conversely, behavior of speculators is identical as retailers' for all of the speculators, whose position at time $t$, on forward delivery period $T$, is short. This assumption allows us to consider only two types of market participants.

Each market participant has to make a present decision (being at time $t$ ) what portion of the future delivery obligation (delivery during time $T$ ) is optimal to hedge and, contrary, what should be the amount kept for speculation.

Producers, which form the supply of electricity on the forward market, can sell the forward contracts and hedge their future revenues now at time $t$, or they can keep the position open and sell their production during the future period, $T$, on the spot market. If we consider that all future producers' supplies are sold through the forward market, the producers' profit rate would be given by the equation:

$$
r_{H}^{P}=\frac{F_{t, T}^{W}-C_{T}}{C_{T}},
$$

Where $r_{H}^{P}$ is the profit rate of a particular producer in the case that all of its production has been sold at the forward price, $F_{t, T}^{W}$. However, total costs, $C_{T}$, are not fixed and are a function of quantity produced and prices of primary energetic sources. We assume that total costs are independent on whether the producer chooses hedging, speculative, or a mixed strategy. Moreover, we suppose that a particular part of variable costs 
(prices of primary energetic sources) are hedged by forward contracts. Parameter $C_{T}$ is therefore exogenous and fixed in a short term period, especially at time $t$. The risk of a fully hedged position is measured by the variance of $r_{H}^{P}$ is equal to zero.

$$
\sigma_{H}^{P}=0
$$

Expected profit rate of the entire speculative position is defined as

$$
r_{S}^{P}=\frac{E\left(S_{T}^{W}\right)-C_{T}}{C_{T}}
$$

The speculative profit rate, $r_{S}^{P}$, is given by the expected spot price for delivery period $T, E\left(S_{T}^{W}\right)$, and production $\operatorname{costs} C_{T}$. The higher the expected spot prices, the higher expected profit from the opened speculative position. On the other hand, there is the risk that the real spot price during period $T$ might be different from producers' expectations. This risk is measured by expected spot prices variance,

$$
\sigma_{S}^{P}>0
$$

Utility of each producer is a positive function of the expected profit. According to the risk aversion, utility is negatively influenced by risk factors, as seen through the equation:

$$
U_{P}(\stackrel{+}{\pi}, \bar{\sigma})
$$

Retailers form the demand on the electricity forward market. They buy energy from producers and resell it to final consumers at price $P_{T}^{R}$. We assume that $P_{T}^{R}$ is well known at time $t$ and fixed on a short term period. When the retailer hedges all of its planned energy purchases via the forward market, the risk free $\left(\sigma_{H}^{R}=0\right)$ profit equals

$$
r_{H}^{R}=\frac{P_{T}^{R}-F_{t, T}^{W}}{F_{t, T}^{W}},
$$

The expected profit of the entire speculative strategy is given by: 
Michalovský, M. - Paholok, I.: Portfolio Theory and Electricity Forward Markets.

$$
r_{S}^{R}=\frac{P_{T}^{R}-E\left(S_{T}^{W}\right)}{E\left(S_{T}^{W}\right)},
$$

which is connected to the risk measured by the expected spot price variance

$$
\sigma_{S}^{R}>0
$$

The utility function of a retailer is positively determined by the expected profit and negatively by the risk of expected profit being realized.

$$
U_{R}(\stackrel{+}{\pi}, \bar{\sigma})
$$

The optimal portfolio structures of the producer, $E\left(S_{T}^{W}\right)>F_{t, T}^{W}$, and the retailer, $E\left(S_{T}^{W}\right)<F_{t, T}^{W}$, are illustrated in a Figure 1. The correlation between the hedged and speculative profit rates are defined as zero.

\section{Figure 1: Optimal portfolio structure}

a./ producer

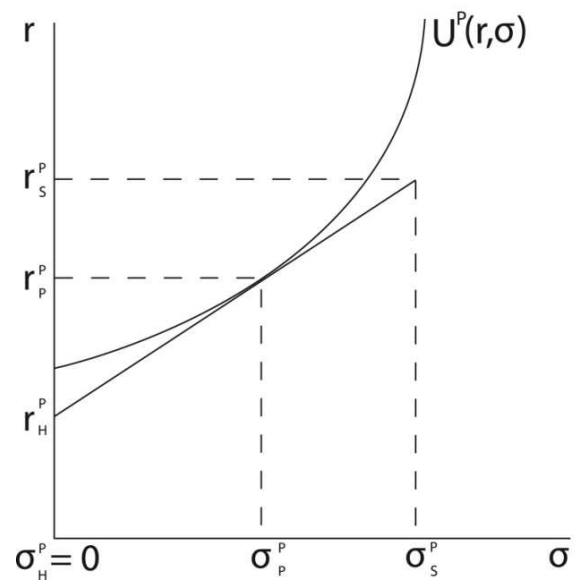

b./ retailer

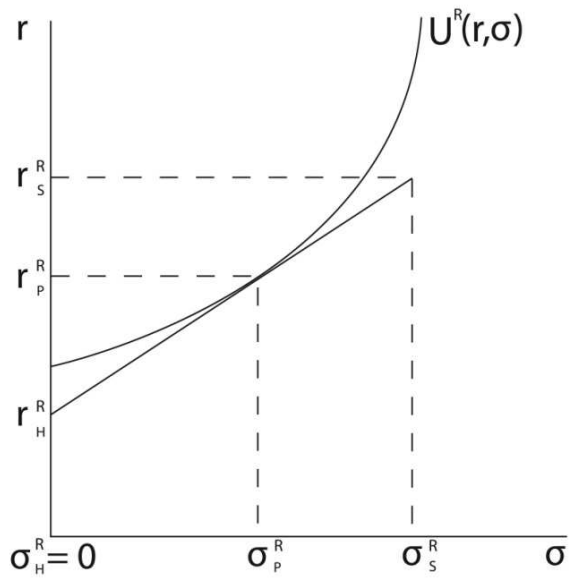

Source: Authors' analyses

The optimum point can be found as the point where the line which represents an achievable portfolio (starting at $\left[\sigma_{H}^{P}=0, r_{H}^{P}\right]$ or 
$\left[\sigma_{H}^{R}=0, r_{H}^{R}\right]$ and ending at $\left[\sigma_{S}^{P}, \pi_{S}^{P}\right]$ or $\left.\left[\sigma_{S}^{R}, r_{S}^{R}\right]\right)$ intersects the tangent line to the utility function (expressed as indifferent curve) of the producer or retailer. Expected profit and risk of the optimal portfolio is given as an optimal composition of risk free and speculative position. Expected profit is denoted as $\left[\sigma_{P}^{P}, r_{P}^{P}\right]$ for producers and $\left[\sigma_{P}^{R}, r_{P}^{R}\right]$ for retailers. The set of admissible portfolios line for producers is defined as

$$
r_{P}^{P}=r_{S}^{P} \frac{\sigma_{P}^{P}}{\sigma_{S}^{P}}
$$

and for retailers as

$$
r_{P}^{R}=r_{S}^{R} \frac{\sigma_{P}^{R}}{\sigma_{S}^{R}}
$$

In accordance with previous model simplification, we assume that $P_{T}^{R}$ and $C_{T}$ are exogenous or fixed in a short term period around time $t$. Henceforth, we can focus on the effects of $E\left(S_{T}^{W}\right)$ and $\sigma_{S}^{P, R}$ changes on the optimal portfolio structure of both producers and retailers. We use mainly graphical analysis, while the optimal portfolio structure can be found mathematically using the Lagrange function by maximizing the utility function ((9) for producers, (13) for retailers) on set of admissible portfolios ((14) for producers and (15) for retailers). Lagrangian (for producers) is defined as

$$
L\left(\sigma_{P}^{P}, r_{P}^{P}, \lambda\right)=U^{P}\left(\sigma_{P}^{P}, r_{P}^{P}\right)+\lambda\left(r_{P}^{P}-r_{S}^{P} \frac{\sigma_{P}^{P}}{\sigma_{S}^{P}}\right),
$$

Conditions for maximization of utility function are given as a partial derivations of the function ( $L$ by parameters $\sigma_{P}^{P}, r_{P}^{P}$ and $\lambda$ ) equal to zero. 
Michalovský, M. - Paholok, I.: Portfolio Theory and Electricity Forward Markets.

$$
\begin{aligned}
& r_{P}^{P}-r_{S}^{P} \frac{\sigma_{P}^{P}}{\sigma_{S}^{P}}=0, \\
& \frac{\partial U^{P}}{\partial \sigma_{P}^{P}}-\lambda \frac{r_{S}^{P}}{\sigma_{S}^{P}}=0, \\
& \frac{\partial U^{P}}{\partial r_{S}^{P}}+\lambda=0 .
\end{aligned}
$$

Derivation for the retailers' case is very similar. The effect of $E\left(S_{T}^{W}\right)$ or $\sigma_{S}^{P, R}$ change can be measured as the difference between optimum before and after change.

Change of $E\left(S_{T}^{W}\right)$ will intuitively cause a change of $F_{t, T}^{W}$. We will examine the transmission via the expected speculative profit of producers and retailers.

From equation (5) we separate $C_{T}$

$$
C_{T}=\frac{F_{t, T}^{W}}{r_{H}^{P}+1},
$$

By substitution to (7) we receive equation for $\pi_{S}^{P}$ as follows:

$$
r_{S}^{P}=\frac{E\left(S_{T}^{W}\right)\left(\pi_{H}^{P}+1\right)}{F_{t, T}^{W}}-1,
$$

It is obvious that the increase of $E\left(S_{T}^{W}\right)$ leads to an increase of $r_{S}^{P}$. The same deduction could be found by directly analyzing the relation (7), but now it is clear that considering the $C_{T}$ level, it is not crucial. The higher expected profit from speculative positions decreases the willingness of producers to hedge their future profit by selling at the forward market. Finally, the lower the supply on the forward market creates a pressure on the forward price to rise. Whole process is illustrated in Fig. 2.a/.

To solve the retailers' part, we separate $P_{T}^{R}$ from equation (10) 


$$
P_{T}^{R}=F_{t, T}^{W}\left(r_{H}^{R}+1\right)
$$

And by adding to (11) we obtain

$$
r_{S}^{R}=\frac{F_{t, T}^{W}\left(r_{H}^{R}+1\right)}{E\left(S_{T}^{W}\right)}-1,
$$

An increase of the expected spot prices lead to a decrease of the speculative profit rate of retailers. Consequently, the demand for forward contracts hedging increases. This whole process is illustrated on Figure 2.b/.

Figure 2: Comparative static after expected spot rate increase

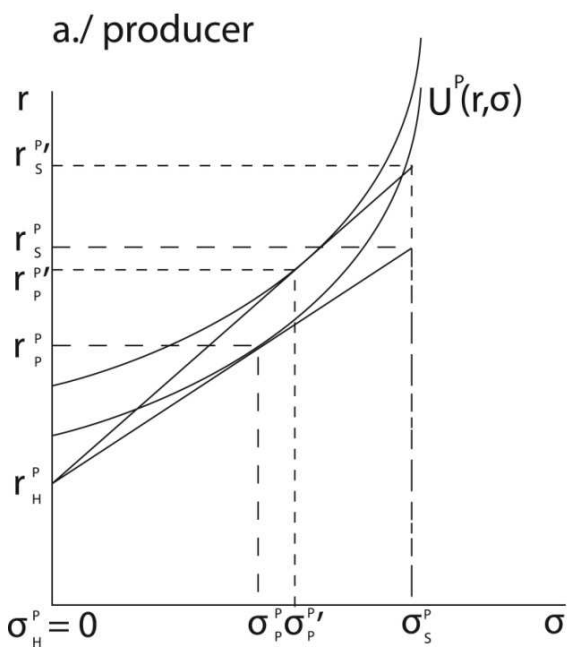
b./ retailer

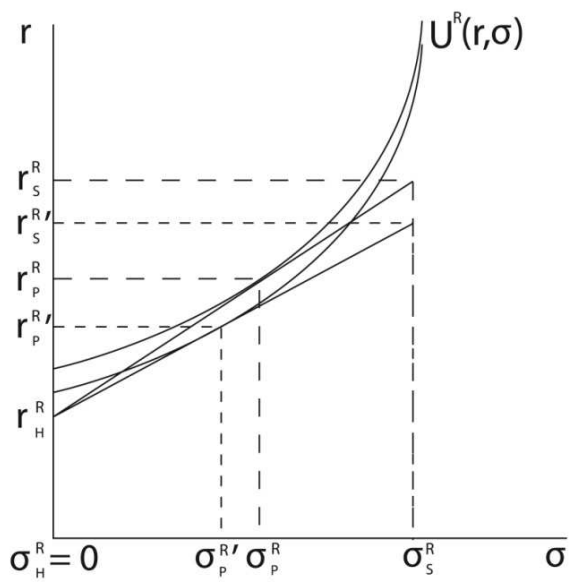

Source: Authors' analyses

The increase of expected spot prices (ceteris paribus) creates pressure on a forward price rise from both groups of market participants. The decrease of expected spot prices has an opposite effect. These findings could be considered as a possible explanation of the transmission between expected spot price and particular forward price in case of non-storable assets.

The consequences of increased risk factors are depicted in Figure 3. The higher the variance of expected spot prices leads to a higher willingness to hedge future cash flow on both sides. Nevertheless, the 
effect on forward price is reversed. Effort of producers to hedge a higher portion of their production forms pressure on the forward price to decrease. Conversely, enhanced retailers' efforts to hedge creates pressure from the demand side, and forward price tends to rise.

\section{Figure 3: Comparative static after spot price variance increase}

\section{a./ producer}

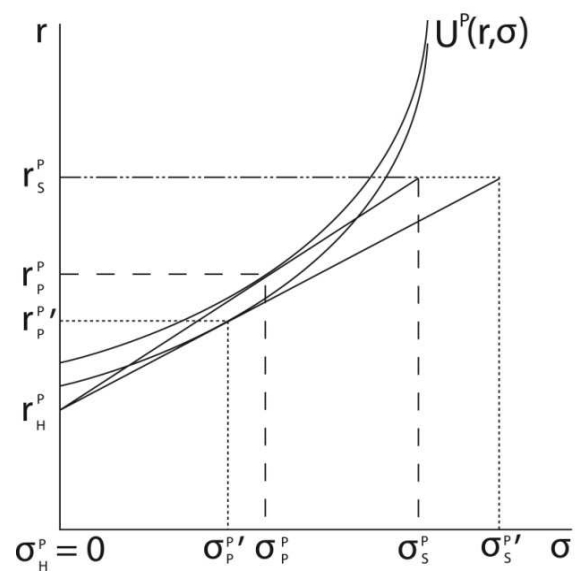

b./ retailer

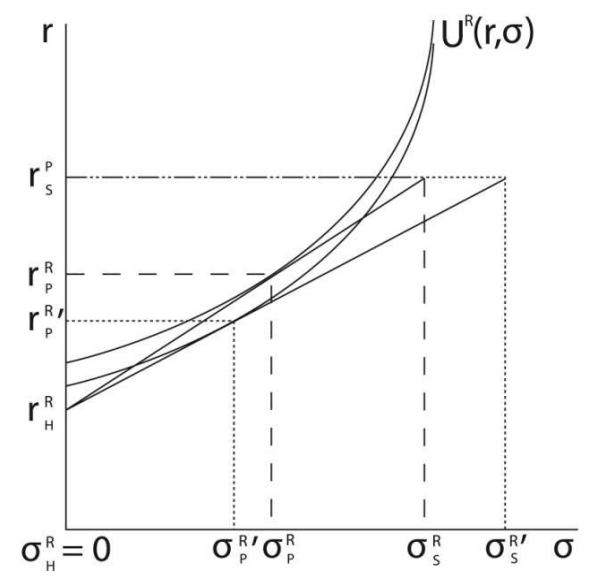

Source: Authors' analyses

We have introduced this model as the electricity forward risk premium model. Comparative static examines the movement of the expected spot price, and explains the empirically observed pattern that risk premium tends to fluctuate around zero as the future price reacts on the expected spot price change. The result of the volatility change (an expected risk factor) remains ambiguous. The higher risk increases the forward price, and consequently the risk premium, when retailers' market position is stronger (given by a market structure, incentive, etc.) than the producers' position, and vice versa.

\subsection{Hypotheses formulation}

We have presented two models, which might be applied in the process of the ex-post risk premium determinants analysis. They are the B-L equilibrium model and the model based on the portfolio theory. The first hypothesis that we intend to test is directly connected to the model's general validity. The statistical adequacy of the model itself is complemented with the verification of the concept's postulates (according 
to Bessembinder and Lemmon (2002)) about the negative linear relation between the particular spot price variance and ex-post risk premium, and the positive linear relation between the particular spot price standardized skewness and the risk premium. On the other hand, applied portfolio theory allows both, positive and negative relations between expected spot price variance and the ex-post risk premium, according to dominance of market participants' positions.

There is still one considerable issue, which needs to be discussed. While B-L equilibrium model presumes the relation between risk premium and risk factors have no time lag (realized variance and skewness of observed spot prices at time $T$ ), the portfolio theory does not explicitly consider whether the risk premium is influenced by realized risk factors or rather by market participants' expectations. Expectation of variance and skewness can be perfect or adaptive, based on a historical data. Therefore, we do not suppose the ability of market participants to predict risk factors is precise and in contrary with the B-L model we do not expect linear relation between the ex-post risk premium and realized variance or skewness of spot prices during the time period $T$. Contrary, we presume the impact of variance or skewness from time horizon $T-1$ and $T-2$ as market participants' expectations are based on historical data. Therefore we provide tests of defined hypotheses with time lags as well.

\section{Empirical tests}

\subsection{Data set}

In this essay we primarily focus on the Power Exchange Central Europe (PXE) located in Prague, Czech Republic. Founded in July 2007, the PXE provides futures contracts for three countries of CEE region the Czech Republic, Slovakia and Hungary. However, the traded volume on PXE is rather low, and therefore we take into consideration the referential European Energy Exchange (EEX) located in Germany as well. In comparison to the Central Europe region, we also decide to analyze patterns in the risk premium on more distant markets where the price can exhibit a different behavior either because of the remoteness and thus connectivity to other markets, or an alternative structure of input for production of electricity. Best for this purpose, we set to analyze the Portuguese division of the Iberian electricity market responsible for 
derivatives (OMIP) and NordPool, the biggest energy exchange in Europe located in Norway.

Both futures and spot prices are obtained from the Bloomberg terminal. The futures time series consists of daily settlement prices of monthly contracts on one-month-ahead basis over period of time from September 2007 to August 2010. These are base-load series only. The first date is chosen with respect to first delivery period on the PXE taking place in October 2007. Because the two lags are included in hypotheses testing, the spot prices begin in August 2007, while ending on the last day in August 2010.They comprise of average daily observations based on 24 hourly prices on day-ahead spot markets. The descriptive statistics of the spot prices are displayed on Tab. 1.

Tab. 1: Descriptive statistics of electricity spot prices, August 2007 August 2010

\begin{tabular}{|l|r|r|r|r|}
\cline { 2 - 5 } \multicolumn{1}{c|}{} & \multicolumn{1}{c|}{$\begin{array}{c}\text { PXE } \\
\text { spot }\end{array}$} & EEX spot & OMEL spot & NordPool spot \\
\hline Mean & 48.28 & 49.27 & 45.86 & 41.53 \\
\hline Median & 43.78 & 44.77 & 40.89 & 40.93 \\
\hline Maximum & 164.78 & 158.97 & 82.13 & 134.80 \\
\hline Minimum & 2.68 & $-35.57 *$ & $0.00^{*}$ & 8.80 \\
\hline Variance & 371.25 & 377.43 & 234.25 & 147.96 \\
\hline Skewness & 1.14 & 1.07 & 0.22 & 0.87 \\
\hline Kurtosis & 4.67 & 5.25 & 2.57 & 6.99 \\
\hline
\end{tabular}

* Zero or even a negative price of electricity is also permitted. For details, see for example Nicolosi (2010). Source: Bloomberg (2011) and authors' analyses

\subsection{Ex-post risk premia}

Firstly, we consolidate the daily data into monthly averages of both the futures and spot prices over the examined period. Then, using the formula (2) for ex-post premium, we get results as drawn on Figure 4. 


\section{Figure 4: One-month-ahead risk premia with kernel density, October 2007 - September 2010}
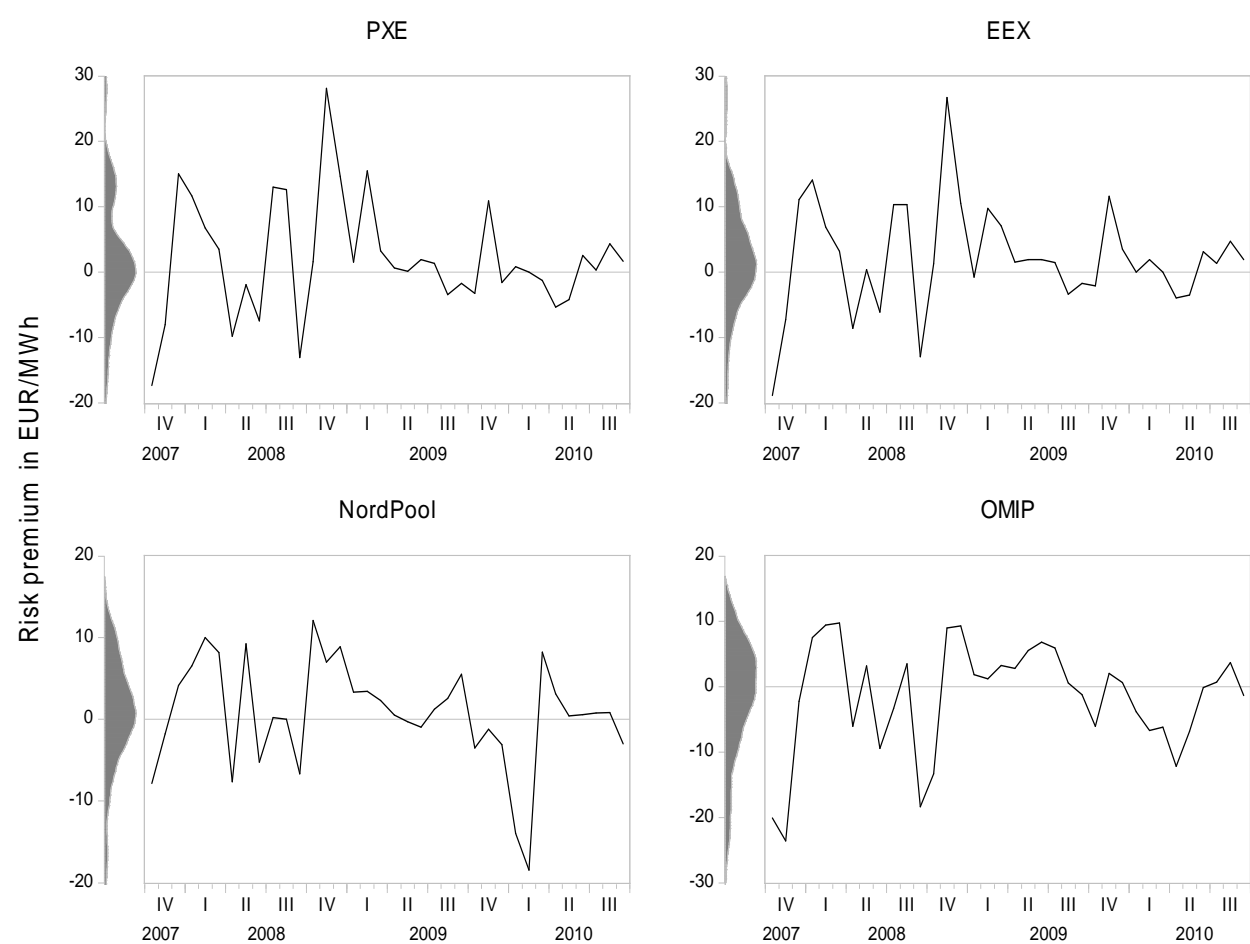

Source: Bloomberg (2011) and authors' analyses

To provide further insight on the results, we test the data on the presence of non-zero risk premium, using the paired two sample t-test for equivalence of means with following results:

Tab. 2: Realized risk premia in EUR/MWh and its t-Statistics

\begin{tabular}{|l|r|r|r|r|}
\cline { 2 - 5 } \multicolumn{1}{c|}{} & \multicolumn{1}{c|}{ PXE } & \multicolumn{1}{c|}{ EEX } & \multicolumn{1}{c|}{ OMIP } & NordPool \\
\hline No. of observations & 36 & 36 & 36 & 36 \\
\hline Average risk premium & 2.06 & 2.17 & -1.51 & 0.72 \\
\hline t-Statistic & 1.38 & 1.59 & -1.07 & 0.66 \\
\hline
\end{tabular}

Source: Bloomberg (2011) and authors' analyses

The average values on each market are without any substantial statistical significance mainly due to only 36 monthly observations are taken into account - restriction imposed by late start of PXE in 2007. However, it can be clearly observed from Figure 4 that the risk premia 
have been subjected to considerable fluctuations throughout the period. In addition, values in Tab. 2 confirm that futures contracts are traded on average with distinct positive risk premium on PXE and EEX, moderate positive premium on NordPool, and negative premium on OMIP.

In the case of PXE and EEX, in Figure 4 we see that the risk premia behave fairly similar with resembling values. This provides evidence that prices on the PXE are largely influenced by price performance on the EEX, seen as referential in Central Europe. Our reasons for choosing to analyze OMIP and NordPool are fully supported by the results. NordPool, which has by far the lowest variance of spot prices as seen in Tab. 1, shows the closest-to-zero risk premium. OMIP, with exceptionally low skewness of spot prices that suggest numerous downward spikes, exhibits the only negative risk premium. This illustrates that markets that are geographically remote from Central Europe contain largely different patterns in electricity price behavior. However, the analyzing of these is beyond the topic of this text, therefore we move to take a closer look at the composition of risk premia.

\subsection{Hypotheses testing}

At the beginning of this subsection we provide a short description of applied methodologies. Statistical testing of the B-L equilibrium model is realized using the multiple linear regression while the statistical testing of other parameters' relevance are based on the simple linear regression. Therefore, whenever we refer to a relation we mean the linear relation.

Adjusted R-square (the coefficient of determination) reveals the explanatory power of a particular model and can be compared across all presented tests. However, the value of adjusted R-square does not exceed 0.25 in any of the examined cases, and we need to point out that the major portion of ex-post risk premium is explained by the difference between expected and realized spot price at time $T$. In other words, variance and skewness of the spot price can explain only a part of the observed (expost) risk premium, while the part is explained by the mistaken spot prices' expectations.

Stationarity of all selected risk premium time series is confirmed by the Unit-root test (augmented Dickey-Fuller test).

The B-L model is originally formulated as equation (4). Results of multiple linear regression are quoted in Tab. 3. 
Tab. 3: B-L equilibrium model multiple linear regression results

\begin{tabular}{|c|c|c|c|c|c|c|}
\hline Area & Statistics & $\mathbf{a}$ & b & c & $\begin{array}{c}\text { Adjusted } \\
\mathbf{R}^{2}\end{array}$ & $\begin{array}{l}\text { DW } \\
\text { test }\end{array}$ \\
\hline \multirow{2}{*}{ PXE } & Coefficient & 1.7776 & 0.0012 & -0.1835 & \multirow{2}{*}{-0.0601} & \multirow{2}{*}{1.4949} \\
\hline & t-statistics & 0.6442 & 0.1308 & -0.0668 & & \\
\hline \multirow{2}{*}{ EEX } & Coefficient & 2.3091 & -0.0000 & -0.0676 & \multirow{2}{*}{-0.0597} & \multirow{2}{*}{1.4588} \\
\hline & t-statistics & 0.9695 & -0.1265 & -0.0362 & & \\
\hline \multirow{2}{*}{ OMIP } & Coefficient & 1.4906 & -0.1160 & 0.3652 & \multirow{2}{*}{0.0860} & \multirow{2}{*}{1.2279} \\
\hline & t-statistics & 0.7948 & -19290 & 0.3502 & & \\
\hline \multirow{2}{*}{ NordPool } & Coefficient & $3.0243 * *$ & $-0.0656 *$ & 0.3770 & \multirow{2}{*}{0.2356} & \multirow{2}{*}{1.8956} \\
\hline & t-statistics & 2.5431 & -33401 & 0.7173 & & \\
\hline
\end{tabular}

Significance of the coefficients at the $1 \%$ and $5 \%$ are indicated with one $\left(^{*}\right)$ or two $(* *)$ asterisks. Source: Bloomberg (2011) and authors' analyses

Results show that the explanatory power of B-L equilibrium model is weak. The only exception is the NordPool data set, where the linear relation between variance and the observed risk premium is statistically significant in confidence 1\% level and negative, what is in compliance with original assumption of B-L equilibrium model. Coefficients for skewness, $c$, are not statistically significant, similarly as coefficients for variance, $b$, for all other examined markets. To provide the entire analysis we reflect to an autocorrelation pattern of EEX (second order autoregressive) and OMIP (first order autoregressive) risk premium data.

Tab. 4: B-L equilibrium model with autoregressive component

\begin{tabular}{|c|c|c|c|c|c|c|c|}
\hline Area & Statistics & $\mathbf{a}$ & $\mathbf{A R}(2)$ & b & c & \begin{tabular}{|c|} 
Adjust- \\
ed $\mathbf{R}^{2}$
\end{tabular} & $\begin{array}{l}\text { DW } \\
\text { test }\end{array}$ \\
\hline \multirow{2}{*}{ EEX } & Coefficient & $4.7898 * *$ & $-0.3548 * *$ & 0.0000 & 1.9818 & \multirow{2}{*}{0.1448} & \multirow{2}{*}{1.5909} \\
\hline & t-statistics & 2.0903 & -2.2566 & 0.0711 & 1.1238 & & \\
\hline Area & Statistics & $\mathbf{a}$ & $\operatorname{AR}(1)$ & b & c & \begin{tabular}{|c|} 
Adjust- \\
ed $\mathbf{R}^{2}$
\end{tabular} & $\begin{array}{l}\text { DW } \\
\text { test }\end{array}$ \\
\hline \multirow{2}{*}{ OMIP } & Coefficient & 1.0885 & $0.3743 * *$ & -0.0697 & -0.1644 & \multirow{2}{*}{0.1868} & \multirow{2}{*}{1.8557} \\
\hline & t-statistics & 0.6523 & 2.4585 & -1.2325 & -0.1574 & & \\
\hline
\end{tabular}

Significance of the coefficients at the $1 \%$ and $5 \%$ are indicated with one $\left(^{*}\right)$ or two $(* *)$ asterisks. Source: Bloomberg (2011) and authors' analyses 
Although coefficients of the determinant are higher than in the case of the pure B-L equilibrium version, the improvement is caused by the autoregressive component only.

In accordance with the provided statistical tests, the B-L equilibrium model does not fit well for all of the selected markets. NeitherVAR $\left[S_{T}\right]$ nor $S K E W\left[S_{T}\right]$ provides enough of a sufficient and general explanation of ex-post risk premia values.

Finally, we provide estimations of simple regression coefficients in Appendix B. We run the following regression:

$$
\pi_{t, T}=\alpha+\beta \cdot \text { factor }_{T=n}+\varepsilon_{t, T},
$$

Calculated variance and skewness of spot prices for time period $\mathrm{T}$, $\mathrm{T}-1$, and $\mathrm{T}-2$ are separately used as the explanatory factor. Tab. 5 shows signs of statistically significant beta coefficients.

Tab. 5: Direction of significant linear relation of tested factors

\begin{tabular}{|c|c|c|c|c|}
\hline Area & PXE & EEX & OMIP & NordPool \\
\hline AR(1) & & & positive* & \\
\hline AR(2) & & negative** & & \\
\hline VAR $_{\mathbf{T}}$ & & & negative** & negative* \\
\hline VAR $_{\mathbf{T}-\mathbf{1}}$ & positive* & positive* & & \\
\hline VAR $_{\mathbf{T}-\mathbf{2}}$ & positive* & positive* & & \\
\hline SKEW $_{\mathbf{T}}$ & & & & \\
\hline $\begin{array}{c}\text { SKEW } \\
\mathbf{T}- \\
\mathbf{1}\end{array}$ & & & & \\
\hline $\begin{array}{c}\text { SKEW } \\
\mathbf{2}-\end{array}$ & & & & \\
\hline
\end{tabular}

Significance of the coefficients at the $1 \%$ and $5 \%$ are indicated with one $(*)$ or two $(* *)$ asterisks. The empty field presents statistically not significant relation. . Source:

Bloomberg (2011) and authors' analyses

The statistically significant positive relation between variances and ex-post risk premia is in discordance with the B-L model, but in conformity with the applied portfolio theory. The hypothesis that variance 
expectations are adaptive, based on historical observations, are confirmed for central European markets. Results for the OMIP and NordPool geographic areas are contradictory. Negative linear relation confirms the assumption of the B-L model. No time lags between the ex-post risk premium and particular variance are statistically significant. Skewness does not significantly explain ex-post risk premia on any of the studied markets.

\section{Conclusion}

In this paper, we look at the behavior of forward risk premiums on four European exchange markets trading electricity futures. We analyze a one-month-ahead base load for electricity contracts over a period of time chosen with regard to the operation of PXE, and energy exchange based in the Czech Republic from October 2007 to September 2010. The risk premia varies substantially on each exchange throughout the period, with positive overall results on EEX and PXE, positive but close to zero results on NordPool, and negative results in OMIP. We find that the development of the risk premia on EEX and PXE is much the same. This suggests a strong influence of referential EEX in the Central European region. The premium in NordPool shows the closest to zero value because of the lowest variability of spot prices. Due to frequent downward spikes and their consequent low skewness of spot prices, OMIP trades with negative risk premium. Although the values of risk premia are clearly distinct, we are unable to statistically verify them with only 36 monthly observations.

We review the equilibrium model proposed by Bessebinder - Lemon (2002). They describe that the risk premium is negatively dependent on the variance of a spot price, and positively dependent on skewness. However, we find that the model in our sample period provides results with little support for their findings. With the exception of NordPool, where the variance coefficient of a spot price is negative and statistically significant giving a reasonable R-square, there are no statistically significant results at all. In addition, R-square coefficients in other exchanges are unusually small.

Therefore, we apply the portfolio theory for both producers and retailers operating on the electricity market. We infer that variance of a spot price can have either a negative or positive influence on the risk 
premium. This is determined by the prevalence of hedging from retailers or producers in the market. When the risk premium is negatively dependent on variance, then there are greater producers' incentives for hedging, and vice versa. Moreover, this application of the portfolio theory allows market participants to adapt their expectations of spot price variances, unlike in the B-L model where the variance is taken as the delivery period, $T$. We thus run our regressions with none, one, and two lags in both variance and skewness to obtain fully comparable results.

In general, the results from the portfolio theory application show higher R-square coefficients of determinations than those of the B-L model. In the case of EEX and PXE, we discover significant dependence of risk premium on lagged variance that suggests adaptive expectations from the participants in these markets.

Finally, we emphasize that the sample period of data in this paper is relatively short, and thus it would be appropriate to consider our findings as valid only over the analyzed period. It has to be pointed out that any regression estimating the risk premium usually has R-square coefficients low enough to say that a major part of the premium is still driven by imperfect estimations of future spot prices by the participants.

\section{References}

[1] Bessembinder, H. - Lemmon, M. (2002): Equilibrium Pricing and Optimal Hedging in Electricity Forward Markets. Journal of Finance, 2002, vol. 57, no. 3, pp. 1347-1382.

[2] Bloomberg (2011): Bloomberg Terminal. [database], New York, Bloomberg, c2011, [extracted $10^{\text {th }}$ April, 2011],

[3] Botterud, A. - Bhattacharyya, A. - Illic, M. (2002): Futures and Spot Prices - An Analysis of the Scandinavian Electricity Market. 34thNorth American Power Symposium, 2002.

[4] Cartea, A. - Villaplana, P. (2008): Spot Price Modeling and the Valuation of Electricity Forward Contracts: The Role of Demand and Capacity. Journal of Banking and Finance, 2008, vol. 32, no. 12, pp. 2502-2519.

[5] Furió, D. - Meneu, V. (2009): Expectations and Forward Risk Premium in the Spanish Deregulated Power Market. Energy Policy, 2010, vol. 38, no. 2, pp. 784-793. 
[6] Hull, J. (2008): Options, Futures and Other Derivatives. Paerson/ Prentice Hall, 2008.

[7] Kodera, J. (2001): Měnová analýza. Slaný, Melandrium, 2001.

[8] Longstaff, F. A. - Wang, A. W. (2004): Electricity Forward Prices: A High-frequency Empirical Analysis. Journal of Finance, 2004, vol. 59, no. 4, pp. 1877-1900.

[9] Lucia, J. - Torro, H. (2008): Short-term Electricity Futures Prices: Evidence on the Time-varying Risk Premium. [on-line], Valencia, University of Valencia, Working Paper, WP-EC 2008-08, c2008, [cit. $10^{\text {th }}$ April, 2011],

<http://www.ivie.es/downloads/docs/wpasec/wpasec-2008-08.pdf>.

[10] Nicolosi, M. (2010): Wind power integration and power system flexibility-An empirical analysis of extreme events in Germany under the new negative price regime. Energy Policy, 2010, vol. 38, no. 11, pp. 7257-7268.

[11] Pietz, M. (2009): Risk Premia in the German Electricity Futures Market. [on-line], München, Technische Universität München, c2009, [cit. 10 ${ }^{\text {th }}$ April, 2011], <http://www.econstor.eu/bitstream/10419/48404/1/616633122.pdf>.

[12] Tobin, J. (1958): Liquidity Preferences as Behaviour towards Risk. Review of Economics Studies, 1958, vol. 73, no. 3, pp. 68-70. 


\section{Appendix A}

Fig. A1: Autocorrelation function of examined markets
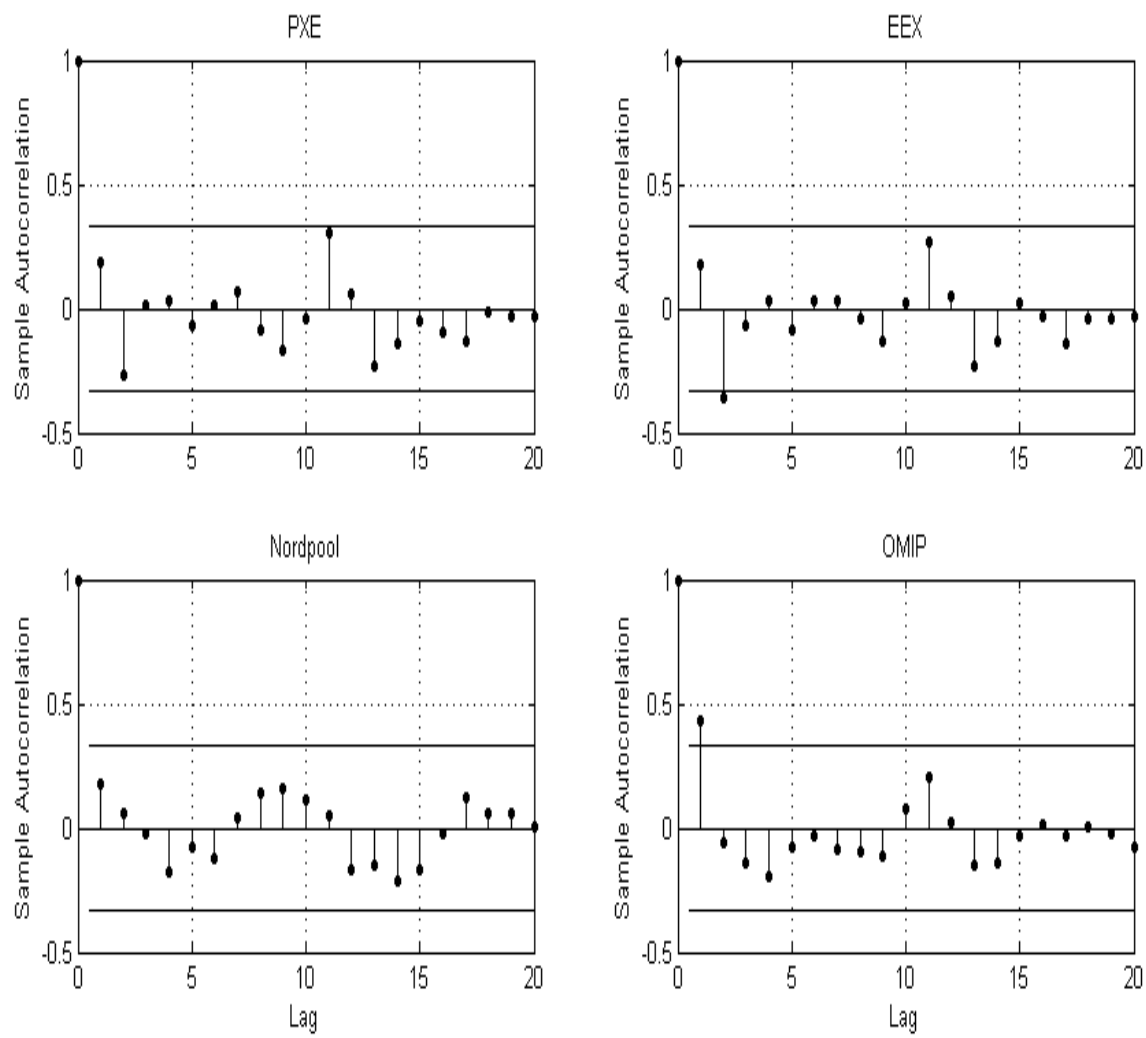

Source: Bloomberg (2011) and authors' analyses 


\section{Appendix B}

Tab. B1: Simple linear regression of PXE ex-post risk premia and selected factors

\begin{tabular}{|c|c|c|c|c|c|c|}
\hline Area & Factor & Statistic & $\alpha$ & $\beta$ & $\begin{array}{c}\text { Adjusted } \\
\mathbf{R}^{\mathbf{2}}\end{array}$ & $\begin{array}{l}\text { DW } \\
\text { test }\end{array}$ \\
\hline \multirow{16}{*}{ PXE } & \multirow[b]{2}{*}{$\mathrm{AR}(1)$} & Coefficient & 2.2175 & 0.1899 & \multirow{2}{*}{0.0128} & \multirow{2}{*}{1.96} \\
\hline & & t-statistic & 1.5331 & 1.2011 & & \\
\hline & \multirow[b]{2}{*}{$\operatorname{AR}(2)$} & Coefficient & 3.4513 ** & -0.2651 & \multirow{2}{*}{0.057} & \multirow{2}{*}{1.4194} \\
\hline & & t-statistic & 2.4354 & -1.7305 & & \\
\hline & \multirow[b]{2}{*}{$\mathrm{VAR}_{\mathrm{T}}$} & Coefficient & 1.8992 & 0.0009 & \multirow{2}{*}{-0.029} & \multirow{2}{*}{1.4877} \\
\hline & & t-statistic & 0.93 & 0.1142 & & \\
\hline & \multirow[b]{2}{*}{$\mathrm{VAR}_{\mathrm{T}-1}$} & Coefficient & -1.9398 & $0.0222 *$ & \multirow{2}{*}{0.2225} & \multirow{2}{*}{1.4784} \\
\hline & & t-statistic & -1.0905 & 3.3194 & & \\
\hline & \multirow[b]{2}{*}{$\mathrm{VAR}_{\mathrm{T}-2}$} & Coefficient & -1.4947 & $0.0198 *$ & \multirow{2}{*}{0.1717} & \multirow{2}{*}{1.8359} \\
\hline & & t-statistic & -0.8161 & 2.8732 & & \\
\hline & \multirow[b]{2}{*}{ SKEW $_{\mathrm{T}}$} & Coefficient & 2.0591 & 0.0072 & \multirow{2}{*}{-0.0294} & \multirow{2}{*}{1.4848} \\
\hline & & t-statistic & 1.2103 & 0.0031 & & \\
\hline & \multirow[b]{2}{*}{ SKEW $_{\mathrm{T}-1}$} & Coefficient & 2.0495 & -0.0219 & \multirow{2}{*}{-0.0294} & \multirow{2}{*}{1.4849} \\
\hline & & t-statistic & 1.2159 & -0.0095 & & \\
\hline & \multirow[b]{2}{*}{$\mathrm{SKEW}_{\mathrm{T}-2}$} & Coefficient & 2.1016 & 0.1472 & \multirow{2}{*}{-0.0293} & \multirow{2}{*}{1.4895} \\
\hline & & t-statistic & 1.2644 & 0.0641 & & \\
\hline
\end{tabular}

Significance of the coefficients at the $1 \%$ and $5 \%$ are indicated with one $(*)$ or two $(* *)$ asterisks. Source: Bloomberg (2011) and authors' analyses 
Michalovský, M. - Paholok, I.: Portfolio Theory and Electricity Forward Markets.

Tab. B2: Simple linear regression of EEX ex-post risk premia and selected factors

\begin{tabular}{|c|c|c|c|c|c|c|}
\hline Area & Factor & Statistic & $\alpha$ & $\beta$ & $\begin{array}{c}\text { Adjusted } \\
\text { R2 }\end{array}$ & $\begin{array}{l}\text { DW } \\
\text { test }\end{array}$ \\
\hline \multirow{16}{*}{ EEX } & \multirow[b]{2}{*}{$\operatorname{AR}(1)$} & Coefficient & 2.3815 & 0.1784 & \multirow{2}{*}{0.0104} & \multirow{2}{*}{1.9462} \\
\hline & & t-statistic & 1.8414 & 1.1658 & & \\
\hline & \multirow[b]{2}{*}{$\mathrm{AR}(2)$} & Coefficient & $3.8217 *$ & $-0.3614 * *$ & \multirow{2}{*}{0.1454} & \multirow{2}{*}{1.5177} \\
\hline & & t-statistic & 3.1858 & -2.5718 & & \\
\hline & \multirow[b]{2}{*}{$\mathrm{VAR}_{\mathrm{T}}$} & Coefficient & 2.3641 & -0.0011 & \multirow{2}{*}{-0.0286} & \multirow{2}{*}{1.456} \\
\hline & & t-statistic & 1.3082 & -0.1684 & & \\
\hline & \multirow[b]{2}{*}{$\mathrm{VAR}_{\mathrm{T}-1}$} & Coefficient & -0.6278 & $0.0158 * *$ & \multirow{2}{*}{0.1412} & \multirow{2}{*}{1.4631} \\
\hline & & t-statistic & -0.3787 & 2.5989 & & \\
\hline & \multirow[b]{2}{*}{$\mathrm{VAR}_{\mathrm{T}-2}$} & Coefficient & -0.6622 & $0.0161 *$ & \multirow{2}{*}{0.1466} & \multirow{2}{*}{1.7379} \\
\hline & & t-statistic & -0.4012 & 2.6477 & & \\
\hline & \multirow[b]{2}{*}{$\mathrm{SKEW}_{\mathrm{T}}$} & Coefficient & 2.0841 & -0.1841 & \multirow{2}{*}{-0.029} & \multirow{2}{*}{1.4624} \\
\hline & & t-statistic & 1.3357 & -0.115 & & \\
\hline & \multirow[b]{2}{*}{$\mathrm{SKEW}_{\mathrm{T}-1}$} & Coefficient & 2.6206 & 0.9873 & \multirow{2}{*}{-0.018} & \multirow{2}{*}{1.458} \\
\hline & & t-statistic & 1.6838 & 0.6185 & & \\
\hline & \multirow[b]{2}{*}{$\mathrm{SKEW}_{\mathrm{T}-2}$} & Coefficient & 2.5327 & 0.8124 & \multirow{2}{*}{-0.0217} & \multirow{2}{*}{1.5099} \\
\hline & & t-statistic & 1.6316 & 0.5078 & & \\
\hline
\end{tabular}

Significance of the coefficients at the $1 \%$ and $5 \%$ are indicated with one (*) or two (**) asterisks. Source: Bloomberg (2011) and authors' analyses 
Tab. B3: Simple linear regression of OMIP ex-post risk premia and selected factors

\begin{tabular}{|c|c|c|c|c|c|c|}
\hline Area & Factor & Statistic & $\alpha$ & $\beta$ & \begin{tabular}{|c|} 
Adjusted \\
R2
\end{tabular} & $\begin{array}{l}\text { DW } \\
\text { test }\end{array}$ \\
\hline \multirow{16}{*}{ OMIP } & \multirow[b]{2}{*}{$\operatorname{AR}(1)$} & Coefficient & -0.3259 & $0.4338 *$ & \multirow{2}{*}{0.1953} & \multirow{2}{*}{1.8865} \\
\hline & & t-statistic & -0.2662 & 3.0416 & & \\
\hline & \multirow{2}{*}{$\operatorname{AR}(2)$} & Coefficient & -0.3963 & -0.0544 & \multirow{2}{*}{-0.0266} & \multirow{2}{*}{1.2607} \\
\hline & & t-statistic & -0.3211 & -0.3827 & & \\
\hline & \multirow[b]{2}{*}{$\mathrm{VAR}_{\mathrm{T}}$} & Coefficient & 1.4477 & $-0.1246 * *$ & \multirow{2}{*}{0.1096} & \multirow{2}{*}{1.2077} \\
\hline & & t-statistic & 0.7837 & -2.3041 & & \\
\hline & \multirow[b]{2}{*}{$\mathrm{VAR}_{\mathrm{T}-1}$} & Coefficient & 0.1137 & -0.0687 & \multirow{2}{*}{0.0130} & \multirow{2}{*}{1.0430} \\
\hline & & t-statistic & 0.0587 & -1.2092 & & \\
\hline & \multirow{2}{*}{ VAR $_{\mathrm{T}-2}$} & Coefficient & -2.0371 & 0.0224 & \multirow{2}{*}{-0.0249} & \multirow{2}{*}{0.9852} \\
\hline & & t-statistic & -1.0334 & 0.3878 & & \\
\hline & \multirow[b]{2}{*}{ SKEW $_{\mathrm{T}}$} & Coefficient & -0.6986 & 1.1922 & \multirow{2}{*}{0.0129} & \multirow{2}{*}{1.0664} \\
\hline & & t-statistic & -0.4502 & 1.2069 & & \\
\hline & \multirow[b]{2}{*}{ SKEW $_{\mathrm{T}-1}$} & Coefficient & -0.5481 & 1.3775 & \multirow{2}{*}{0.0275} & \multirow{2}{*}{1.0703} \\
\hline & & t-statistic & -0.3543 & 1.4102 & & \\
\hline & \multirow[b]{2}{*}{$\mathrm{SKEW}_{\mathrm{T}-2}$} & Coefficient & -1.2241 & 0.4059 & \multirow{2}{*}{-0.0245} & \multirow{2}{*}{1.0187} \\
\hline & & t-statistic & -0.7700 & 0.4044 & & \\
\hline
\end{tabular}

Significance of the coefficients at the $1 \%$ and $5 \%$ are indicated with one (*) or two (**) asterisks. Source: Bloomberg (2011) and authors' analyses 
Michalovský, M. - Paholok, I.: Portfolio Theory and Electricity Forward Markets.

Tab. B4: Simple linear regression of NordPool ex-post risk premia and selected factors

\begin{tabular}{|c|c|c|c|c|c|c|}
\hline Area & Factor & Statistic & $\alpha$ & $\beta$ & \begin{tabular}{|} 
Adjusted \\
R2
\end{tabular} & $\begin{array}{l}\text { DW } \\
\text { test }\end{array}$ \\
\hline \multirow{16}{*}{ NordPool } & \multirow{2}{*}{$\operatorname{AR}(1)$} & Coefficient & 0.8129 & 0.1826 & \multirow{2}{*}{0.0055} & \multirow{2}{*}{2.0135} \\
\hline & & t-statistic & 0.7447 & 1.0906 & & \\
\hline & \multirow{2}{*}{$\operatorname{AR}(2)$} & Coefficient & 0.9931 & 0.0613 & \multirow{2}{*}{-0.0272} & \multirow{2}{*}{1.6341} \\
\hline & & t-statistic & 0.8719 & 0.3562 & & \\
\hline & \multirow{2}{*}{$\mathrm{VAR}_{\mathrm{T}}$} & Coefficient & $2.8841 * *$ & $-0.0623 *$ & \multirow{2}{*}{0.2551} & \multirow{2}{*}{1.8897} \\
\hline & & t-statistic & 2.5957 & -3.6039 & & \\
\hline & \multirow{2}{*}{$\mathrm{VAR}_{\mathrm{T}-1}$} & Coefficient & 0.8896 & -0.0049 & \multirow{2}{*}{-0.0277} & \multirow{2}{*}{1.6066} \\
\hline & & t-statistic & 0.6799 & -0.2396 & & \\
\hline & \multirow{2}{*}{$\mathrm{VAR}_{\mathrm{T}-2}$} & Coefficient & 0.0734 & 0.0184 & \multirow{2}{*}{-0.0047} & \multirow{2}{*}{1.5486} \\
\hline & & t-statistic & 0.0567 & 0.9147 & & \\
\hline & \multirow{2}{*}{$\mathrm{SKEW}_{\mathrm{T}}$} & Coefficient & 0.6320 & -1.1779 & \multirow{2}{*}{0.0073} & \multirow{2}{*}{1.6621} \\
\hline & & t-statistic & 0.5842 & -1.1218 & & \\
\hline & \multirow{2}{*}{$\mathrm{SKEW}_{\mathrm{T}-1}$} & Coefficient & 0.6325 & -1.5535 & \multirow{2}{*}{0.0341} & \multirow{2}{*}{1.5608} \\
\hline & & t-statistic & 0.5933 & -1.4949 & & \\
\hline & \multirow{2}{*}{$\mathrm{SKEW}_{\mathrm{T}-2}$} & Coefficient & 0.7245 & 0.2437 & \multirow{2}{*}{-0.0279} & \multirow{2}{*}{1.5609} \\
\hline & & t-statistic & 0.6597 & 0.2224 & & \\
\hline
\end{tabular}

Significance of the coefficients at the $1 \%$ and $5 \%$ are indicated with one $(*)$ or two $(* *)$ asterisks. Source: Bloomberg (2011) and authors' analyses 


\title{
Portfolio Theory and Electricity Forward Markets
}

\author{
Michal MICHALOVSKÝ - Igor PAHOLOK
}

\begin{abstract}
In the discussion on the relationship between spot and forward prices in electricity markets, the equilibrium approach has an unambiguous prevalence. It is the relative recency of this market that gives rise to the question of how precisely forward prices converge to the spot prices. We decide to measure this convergence, with its eventual imbalance called risk premium, on several European energy exchanges trading electricity futures. The concept of risk premium, as it is worked out by Bessembinder and Lemon (2002) is reviewed in our essay through the Markowitz portfolio theory. Unlike in the B-L model, where the variance of the spot price has a strictly negative relationship to the risk premium, it is shown that the portfolio theory gives us a different inference that the variance can have both negative and positive impacts according to the strength of supply and demand in the market. This empirically tested and found appropriate. Positive dependence of variance in the electricity markets have been found in Central Europe and Scandinavia, while in Iberian the results are still negative.
\end{abstract}

Key words: Portfolio theory; B-L equilibrium model; Electricity forward markets.

JEL classification: G13, Q41, L11. 